\title{
Early detection of gastric cancer
}

\author{
M T Hallissey, W H Allum, A J Jewkes, D J Ellis, J W L Fielding
}

\begin{abstract}
Objective-To see whether investigation of dyspeptic patients aged over $\mathbf{4 0}$ after their first consultation with the general practitioner would increase the proportions with early and operable gastric cancers.

Design-Prospective study of gastric cancer in dyspeptic patients aged over $\mathbf{4 0}$ from a defined population.
\end{abstract}

Setting-10 General practices (six in central Birmingham, four in Sandwell); the Queen Elizabeth Hospital, Birmingham; and Sandwell District General Hospital.

Patients -2659 Patients aged 40 or over referred with dyspepsia.

Main outcome measure-Increase in early and operable gastric cancers detected in middle aged patients with dyspepsia.

Results-Disease was identified in 1992 patients $(75 \%)$. Fifty seven were found to have gastric cancer, 36 being treated by potentially curative resection, including 15 with early cancer.

Conclusions-The investigation of dyspeptic patients over $\mathbf{4 0}$ at first attendance can increase the proportion of early gastric cancers detected to $26 \%$ and the proportion of operable cases to $63 \%$. Such a policy has the potential to reduce mortality from gastric cancer in the population.

\section{Introduction}

Survival in patients with gastric cancer is dependent on the stage at which the diagnosis is made. In the United Kingdom gastric cancer accounts for 11200 deaths a year, making it the fourth most common cause of death from malignant disease. ${ }^{1}$ The overall five year survival of these patients is just $5 \%$, which reflects the late stage at which so many present. ${ }^{2}$ The diagnosis, however, can be made at a stage when long term survival is achievable. In Japan treating early disease results in a five year survival of $97 \% .^{3}$ To have an impact on the mortality from the disease in the community as a whole it is essential that there should be a major change in the stage of the disease at the time of diagnosis.

The Japanese have shown the effectiveness of mass screening by indirect radiology. ${ }^{4}$ In the United Kingdom, however, the lower incidence of the disease makes such a programme unrealistic. Hence identifying high risk groups has been suggested as a means of changing the stage of the disease at the time of diagnosis. The groups suggested have been based on genetic factors, occupation, environment, or disease. Investigating these groups, however, would not identify enough cases to change the mortality within a community.

Most patients with gastric cancer present with symptoms referable to the upper gastrointestinal tract, ${ }^{5}$ and nearly half of the early gastric cancers detected by screening are in patients who have symptoms. ${ }^{6}$ Examination of consultation rates in general practice shows that a population of 100000 will include 1590 patients who present with dyspeptic symptoms. Of these, 30 will have gastric cancer and in over 1000 no firm diagnosis will be made. The peak incidence of gastric cancer occurs in the sixth and seventh decades, so that investigation of dyspeptic patients over the age of 40 is potentially a practical way of influencing the stage of the disease at diagnosis.

Certain mucosal changes are associated with an increased risk of gastric cancer. They include atrophic gastritis, ${ }^{78}$ intestinal metaplasia, ${ }^{910}$ dysplasia, ${ }^{11}$ and gastric polyps. ${ }^{12}$ These changes can be identified only by biopsy of the stomach, usually during endoscopy. Regular endoscopy in patients with these changes may further increase the detection of early disease.

A programme has been developed in which patients over 40 presenting with dyspepsia for the first time have been referred for early endoscopy to determine the pattern of detection of gastric cancer and to see whether the proportions of early and curable lesions can be increased. Findings in the initial 650 patients have been reported. ${ }^{13}$

\section{Subjects and methods}

The study began in April 1984 with six general practices within the City of Birmingham that were responsible for 64000 patients. Four further practices responsible for 45000 patients were added from the Sandwell district of the West Midlands in January 1986. Recruitment was completed at the end of December 1988.

General practitioners were asked to refer all patients over 40 making their first attendance during the study period with any degree of dyspepsia. ${ }^{14}$ Patients were initially interviewed and examined by a member of the hospital team at special dyspepsia clinics held in the general practitioners' surgeries within two weeks after presentation. Their symptoms were recorded and classified as mild upper abdominal discomfort, ulcer type pain, continuous epigastric pain, or symptoms of oesophageal or pyloric obstruction. ${ }^{5}$ Patients were offered an upper gastrointestinal endoscopy and asked to attend the hospital the following week for examination.

Endoscopy was performed on a day case basis under sedation with an intravenous benzodiazepine. Patients from the Birmingham practices were examined at the Queen Elizabeth Hospital, Birmingham, and from the Sandwell practices at Sandwell District General Hospital. Examinations were performed by a consultant or experienced registrar. Any areas of abnormality were documented. When the abnormality was in the stomach a biopsy sample was taken for histological diagnosis and the area brushed for cytology. Patients with normal appearances were referred the same day for ultrasound examination of the gall bladder.

A full report was sent to the general practitioner 
including the histological and cytological findings. Patients with benign disease were managed by their general practitioner. Those with a gastric ulcer were re-examined at two month intervals after medical treatment from their general practitioner until healing occurred. Those with gastric polyps or the potentially premalignant histological changes of chronic atrophic gastritis, intestinal metaplasia, or dysplasia - the high risk disorders group - had annual follow up endoscopy. Patients with malignant disease were referred for appropriate management. Those patients whose endoscopic findings were normal despite troublesome symptoms were investigated further.

\section{Results}

Patients-Based on current population statistics roughly 45000 patients in the study population were aged over 40 . During the study period (four years and nine months) 2659 patients were seen at the dyspepsia clinics and 2585 attended for investigation. The group was equally divided among new patients with dyspepsia, old patients with dyspepsia that had not been investigated, and old patients with dyspepsia that had been investigated. Compliance was high, $95 \%$ of patients attending the clinic after the consultation with their general practitioner and $97 \%$ of these patients attending for endoscopy.

TABLE I-Distribution of diagnoses at each centre. Figures are numbers of patients

\begin{tabular}{lccc}
\hline & $\begin{array}{c}\text { Queen } \\
\text { Elizabeth } \\
\text { Hospital, } \\
\text { Birmingham }\end{array}$ & $\begin{array}{c}\text { Sandwell } \\
\text { District }\end{array}$ & \\
General & Hospital & Total (\%) \\
Diagnosis & & & \\
\hline Hiatus hernia and oesophagitis/ & 311 & 190 & $501(19)$ \\
$\quad$ hiatus hernia alone & 32 & 25 & $57(2)$ \\
Gastric cancer & 253 & 73 & $326(12)$ \\
High risk disorder & 100 & 67 & $167(6)$ \\
Gastric ulcer & 302 & 103 & $405(15)$ \\
Gastritis & 145 & 118 & $263(10)$ \\
Duodenal ulcer & 58 & 55 & $113(4)$ \\
Duodenitis & 42 & 16 & $58(2)$ \\
Other cancers & 223 & 370 & $593(22)$ \\
Normal & 50 & 16 & $66(2)$ \\
Gall stones & 18 & 18 & $36(1)$ \\
Other & 41 & 33 & $74(3)$ \\
Did not attend & 1575 & 1084 & $2659(100)$ \\
\hline Total & & & \\
\hline
\end{tabular}

TABLE II -Stages of gastric cancers in patients eligible for operation

\begin{tabular}{lcccccc}
\hline Stage: & I & II & III & IVA & IVB & Total \\
\hline No of patients: & 12 & 7 & $17^{\star}$ & 8 & 12 & $56 \dagger$
\end{tabular}

${ }^{\star}$ Includes three patients with node positive early gastric cancer. fOne patient refused surgery.

TABLE III - High risk disorders found among 2659 patients referred

\begin{tabular}{lccccccc}
\hline High risk disorder: & $\begin{array}{c}\text { Gastric } \\
\text { ulcer }\end{array}$ & $\begin{array}{c}\text { Gastric } \\
\text { polyps }\end{array}$ & Dysplasia & $\begin{array}{c}\text { Intestinal } \\
\text { metaplasia }\end{array}$ & $\begin{array}{c}\text { Atrophic } \\
\text { gastritis }\end{array}$ & $\begin{array}{c}\text { Foveolar } \\
\text { hyperplasia }\end{array}$ & Total \\
\hline No(\%) of patients: & $167(6)$ & $36(1)$ & $48(2)$ & $185(7)$ & $34(1)$ & $23(1)$ & $493(19)$ \\
\hline
\end{tabular}

TABLE IV - Accuracy of diagnosis of gastric cancer

\begin{tabular}{|c|c|c|c|c|c|}
\hline \multirow[b]{2}{*}{ Stage } & \multirow[b]{2}{*}{$\begin{array}{l}\text { No of patients } \\
\text { eligible for } \\
\text { operation }\end{array}$} & \multicolumn{2}{|c|}{ No diagnosed clinically by: } & \multicolumn{2}{|c|}{ No diagnosed at first endoscopy } \\
\hline & & $\begin{array}{c}\text { General } \\
\text { practitioners } \\
\text { before referral }\end{array}$ & $\begin{array}{l}\text { Hospital doctor } \\
\text { at dyspepsia } \\
\text { clinic }\end{array}$ & Macroscopically & Histologically \\
\hline I & 12 & 1 & & 2 & 4 \\
\hline II & 7 & 2 & 2 & 2 & 5 \\
\hline III & 17 & & 1 & 11 & 13 \\
\hline IVA & 8 & & 2 & 5 & 7 \\
\hline IVB & 12 & 2 & 7 & 11 & 12 \\
\hline Total & $56^{\star}$ & 5 & 12 & 31 & 41 \\
\hline
\end{tabular}

ॠOne patient refused surgery.
Endoscopic findings - Table I shows the distribution of diagnoses at each centre. Of the $593(22 \%)$ patients considered to have normal appearances on endoscopy, a substantially smaller proportion had been examined in Birmingham. The difference in the proportions of patients with normal findings between the two centres (223/1575 (14\%) in Birmingham; 370/1084 (34\%) at Sandwell) was partly explained by the lower proportion of patients with high risk disorders and gastritis at Sandwell and may have reflected differences in the threshold for sampling the gastric mucosa for biopsy. Malignancy was detected in 115 patients (4\%), 57 of whom had gastric adenocarcinoma and one a gastric lymphoma. The frequency of gastric cancer in the study group was one in 47 . The non-gastric cancers included 15 carcinomas of the oesophagus, of which two were adenocarcinomas confined to the oesophagus and 13 squamous carcinomas. Other malignancies were colorectal ( 14 cases), pancreatic (6), bronchial (8), prostatic (2), duodenal (1), liver (1), gall bladder (1), carcinoid (1), uterine (1), leukaemia (1), and carcinomatosis in which a primary site could not be identified (7). Apart from the oesophageal lesions detected at endoscopy, these cases were diagnosed after further investigation of symptoms or signs considered to be consistent with an underlying malignancy.

Stage of gastric cancer-Table II shows the stages of the gastric cancers detected by endoscopy. There were 12 patients whose carcinoma was confined to the mucosa and submucosa alone. In a further three cases lymph node metastases were identified, though the primary tumour was limited to the mucosa and submucosa. Hence in 15 cases (26\%) the gastric cancer would be classified as early according to the rules of the Japanese Research Society for Stomach Cancer. ${ }^{3}$ The staging system used was based on operative findings in addition to conventional histological criteria which included $\mathrm{N}_{3}$ node biopsy, ${ }^{15}$ so that patients with stages I-III disease had macroscopic and microscopic clearance and patients with stage IV disease had residual tumour. ${ }^{15}$ All but two of the 57 patients came to laparotomy. One was considered unfit and the second refused. Potentially curative surgery was possible in $36(63 \%)$ cases.

High risk disorders included gastric ulcers or polyps together with dysplasia, intestinal metaplasia, or chronic atrophic gastritis on biopsy (table III). The proportion of the overall series with these lesions was $19 \%$ (493 patients). All were reviewed by follow up endoscopy. Ten of the gastric cancers were identified during follow up of these high risk disorders, six of the 10 being limited to the mucosa and submucosa. Nine of the 10 cancers were detected within 14 months after the original endoscopy, the remaining cancer being identified at the fourth annual follow up endoscopy.

Accuracy of diagnosis of gastric cancer-The clinical diagnosis in each patient was recorded by the general practitioner before referral and by the hospital doctor at the dyspepsia clinic. Table IV gives the results in the patients with gastric cancer. Neither the general practitioner nor the hospital doctor was accurate in diagnosing gastric malignancy at any stage, although seven of the 12 advanced lesions were correctly diagnosed by the hospital doctor. The accuracy of the macroscopic assessment of the lesion at first endoscopy was also determined (table IV). For advanced lesions diagnostic accuracy was high, 28 of the 41 such cancers being correctly identified. Early lesions, however, were less reliably identified, only three of 15 being correctly diagnosed at the initial examination. The accuracy of histological diagnosis was also low for the early lesions, reflecting the difficulties of obtaining a representative biopsy sample and showing the value of selecting high risk patients for follow up endoscopy. 


\section{Discussion}

This study aimed at identifying and screening high risk groups for gastric cancer. The excellent survival after surgery for early lesions ${ }^{3}$ and the failure of currently available adjuvant treatments to improve survival ${ }^{16}$ make it essential that methods of detecting early disease should be investigated.

Open access endoscopy provides a useful diagnostic service for upper gastrointestinal symptoms. ${ }^{17}{ }^{18}$ Nevertheless, it failed to change the pattern of disease, and critics have suggested that the large numbers of normal results obviate the advantage of early diagnosis. ${ }^{19}$ Scoring systems for risk factors and symptom profiles have been evaluated to increase the yield of endoscopy. ${ }^{201}$ These profiles, however, are based on those preselected patients attending an open access service, and those with the most reliable scores describe the symptoms of advanced disease.

Open access endoscopy has also failed to change the pattern of referral by general practitioners. There has been no change in the delay between first consultation and referral to either an open access service or an outpatient department, ${ }^{19}$ and there has been no evidence of a change in the group being referred. The three features of this study which differentiate it from other reports are an attempt to remove selection by general practitioners, a reduction in the delay before referral and diagnosis, and the further examination of patients with high risk mucosal abnormalities.

The design of the study resulted in the rate of detection of gastric cancer which was expected from the Office of Population Censuses and Surveys figures for general practitioner consultations. ${ }^{22}$ An additional finding, and possibly of equal relevance, was the prevalence of both gastrointestinal and other cancers occurring within this population of patients. The finding that $4 \%$ of patients presenting with dyspepsia had an underlying malignancy was unexpected. Indeed, many of the patients with gastric cancer would have been excluded from further assessment had a symptom profile been used. Furthermore, the low accuracy of clinical diagnosis of gastric cancer recorded in the study indicates the need for a low threshold to investigate these patients. It is this approach that resulted in the increased rate of detection of early lesions.

In identifying this group of patients with malignant disease a large number of patients were investigated. Though debate continues about the reassurance value of obtaining normal findings on endoscopy, there can be no doubt that endoscopy allowed treatment to be targeted more effectively in patients with benign disease. The relevance of the "high risk" histological abnormalities remains to be established. Though they formed a large group, the identification of 10 cancers on follow up highlights their importance, particularly as six were early lesions. Long term follow up in these patients is continuing to assess the risks that these changes carry and the value of follow up.

In the context of other forms of cancer screening this study suggests that selective screening for gastric cancer should be pursued. For example, for cervical cancer, which is responsible for 2000 deaths a year, cytology screening identified one early cancer for every 330 women examined. Similarly, screening for breast cancer by mammography detects one early case for every 900 women investigated. Our findings show that one early case of gastric cancer is detected for every 177 patients examined. As gastric cancer kills over 10000 people a year the potential of early diagnosis is self evident.

This study shows how close cooperation between hospital staff and the general practitioner results in an efficient and effective service. The importance of full and clear instruction of the general practitioner before the study was paramount. After establishing such a relationship it proved possible to omit the dyspepsia clinics and use direct referral. Early and regular communications are essential to this type of service and require secretarial help within the hospital. The training of endoscopists to the necessary standard is straightforward and these staff do not need to be permanent hospital staff. For a district with a population of around 250000 this service would investigate roughly 28 new cases a week. In this study only one of the 57 cases of gastric cancer was in a patient aged under 55 . Therefore, it might be possible to reduce the number of endoscopies by raising the age limit from 40 to 55 without serious adverse effects on the effectiveness of the programme.

Gastric cancer is a substantial problem which has proved difficult to manage. The methods used in this study increased the proportion of cancers detected as early lesions from $1 \%$ to $26 \%$. Similarly, the proportion of potentially curative resections rose from $20 \%$ to $63 \%$. Although improvements and modifications to the design are possible, due consideration needs to be given to the implementation of such a programme in clinical practice.

This study is reported on behalf of the British Stomach Cancer Group. MTH, WHA, and AJJ received grants from the Cancer Research Campaign. We thank the following general practitioners for entering their practices and patients into the study and for their support in the work: Drs L Pike, I Cox, M Clarkson, A Thake, D Crombie, A Benn, M Edward, W van Marle, K Bhogal, M Simpson, E Hamnett, C Green, D Fleming, V Tudor, D Barford, D Kinch, A Ross, N Chauhan, S Meux, V Rao, G Campbell, P Preston, F Campbell, D Johnston, M Mortimer, J Kay, R Palmer, J Waters, C Phillips, $M$ Lucy, P Borg-Bartolo, $M$ Taylor, J Glennie, C Morris, S Bathija, H Nutbeam, B Conochie, D Beveridge, G Holtom, B Andreou, A Bevan, J Baker, K Srivastava, E Carter, D Huey, J Tyler, H Shaw, J Strong, P Gibson, M Hyman, N Mewar, J Briant, C Binks, B Rothwell, I Young, S Collier, and F Crocker.

1 Office of Population Censuses and Surveys. Cancer statistics. London: HMSO, 1986.

2 Allum WH, Powell DJ, McConkey CC, Fielding JWL. Gastric cancer: a 25 year review. Br J Surg 1989;76:535-40.

3 Murakami T. Early cancer of the stomach. World F Surg 1979;3:685-92.

4 Hisamichi S, Sugawara N. Mass screening for gastric cancer by $x$ ray examination. $f p n f$ Clin Oncol 1984;14:211-23.

5 Swynnerton RF, Truelove SC. Carcinoma of the stomach. Br Med $f$ 1952;i:287-92

6 Hisamichi S, Nozaki K, Kitagawa M, et al. Evaluation of mass screenin program for stomach cancer. Tohoku f Exp Med 1976;118(suppl):69-77.

7 Walker IR, Strickland RG, Ungar B, MacKay IR. Simple atrophic gastritis and gastric carcinoma. Gut 1971;12:906-11.

8 Siurala M, Varis K, Wiljasalo M. Studies of patients with atrophic gastritis: 10-15 year follow-up. Scand $\mathcal{F}$ Gastroenterol 1966;1:40-8.

9 Morson BC. Intestinal metaplasia of gastric mucosa. Br f Cancer 1955;9: 365-76.

10 Morson BC. Carcinoma arising from areas of intestinal metaplasia in the gastric mucosa. Brf Cancer 1955;9:377-85.

11 Morson BC, Sobin LH, Grundmann E, Johansen A, Nagayo T, SerckHanssen A. Precancerous conditions and epithelial dysplasia in the stomach. f Clin Pathol 1980;33:711-21.

12 Harju E. Gastric polyposis and malignancy. Br $\mathcal{Y}$ Surg 1986;73:532-3.

13 Allum WH, Hallissey MT, Ambrose NS, Dorrell AS, Lowe J, Fielding JWL. Programme for early detection of gastric cancer. Br Med f 1986;293:541.

14 Working Party on Management of Dyspepsia. Report. Lancet 1988;i:576-9.

15 Fielding JWL, Ellis DJ, Jones BG, et al. Clinicopathological staging of gastric adenocarcinoma. Clinical Oncology 1983;9:86.

16 Allum WH, Hallissey MT, Kelly KA. Adjuvant chemotherapy in operable gastric cancer: 5 year follow up of the first British stomach cancer group trial. Lancet 1989; i:571-4.

17 Gear MWL, Ormiston MC, Barnes RJ, Rocyn-Jones J, Voss GC. Endoscopic studies of dyspepsia in the community: an "open access" service. Br Med $\mathcal{f}$ 1980;280:1135.

18 Gear MWL, Barnes RJ. Endoscopic studies of dyspepsia in a general practice. BrMed f 1980;280:1136-7.

19 Holdstock G, Bruce S. Endoscopy and gastric cancer. Gut 1981;22:673-6.

20 Davenport PM, Morgan AG, Darnborough A, de Dombal FT. Can preliminary screening of dyspeptic patients allow more effective use of investigational techniques? BrMed f 1985;290:217-20.

21 Mann J, Holdstock G, Harman M, Machin D, Loehry CA. Scoring system to improve the cost effectiveness of open access endoscopy. $\mathrm{Br}$ Med 1983;287:937-40

22 Office of Population Censuses and Surveys. Mortality statistics for general practice. Second national study 1970-1972. London: HMSO, 1972.

(Accepted 13 fune 1990) 